\title{
DOMINASI KEDAULATAN NEGARA DALAM INTEGRASI PEMERINTAHAN UNI EROPA: PENOLAKAN YUNANI TERHADAP PENGUNGSI SYRIA
}

\author{
Hirshi Anadza \\ Fakultas Ilmu Administrasi, Universitas Islam Malang \\ email: hirshi.anadza@unisma.ac.id
}

\begin{abstract}
Integration becomes a solution when global government does not have capability to overcome power domination of state. By having integration, it is expected that all of member state can put all their authority in supranational governance, such as European Union (EU) so balance could be happen. By giving such kind of integration, the agreement of policies can be followed by the members of EU based on solidarity and tolerance among the members. However, this integration has not succeeded in reducing domination of country sovereignty that influences the variety of each country necessity, even it happen in not powerful state. This phenomenon is reflected when Greece broke the agreement of EU policy related to refugees protection, called Common European Asylum System (CEAS), by refuse asylum seekers from Syria. There are two things that must be highlighted when Greece refuse asylum seekers from Syria. First, domestic problem that can restrain Greece government in obeying CEAS policies. Second, the value of tolerance and solidarity from other countries has not be adhered in the policies agreed by each members of EU. Therefore, this paper explain further about studies to find the relationship between integration in supranational governance and country sovereignty.
\end{abstract}

Keyword: integration, sovereignty, European Union, refugees.

\begin{abstract}
ABSTRAK
Integrasi bisa menjadi solusi ketika pemerintahan global tidak memiliki kemampuan untuk mengatasi permasalahan dominasi kekuatan suatu negara. Dengan integrasi, semua negara diharap bisa menyerahkan otoritasnya kepada pemerintahan supranasional, seperti Uni Eropa (EU) supaya terjadi keseimbangan antar negara. Dengan integrasi seperti itu, sebuah kebijakan EU bisa diterapkan oleh negara anggotanya dengan dasar solidaritas dan toleransi antar anggota negara. Namun, integrasi semacam ini masih belum sukses dalam rangka mengurangi dominasi kedaulatan salah satu negara yang memiliki kebutuhan tersendiri, bahkan hal ini terjadi di negara yang tidak terlalu kuat. Fenomena ini tergambarkan ketika Yunani melanggar kesepakatan dalam kebijakan EU berkenaan dengan masalah perlindungan pengungsi yang bernama Common European Asylum System (CEAS) dengan menolak pencari suaka dari Syria. Ada dua hal yang perlu digarisbawahi dalam penolakan Yunani terhadap pencari suaka dari Syria. Pertama, masalah domestik yang menghambat pemerintah Yunani menjalankan aturan-aturan CEAS. Kedua, nilai toleransi dan solidaritas dari negara anggota EU yang tidak muncul dalam pelaksanaan aturan bersama. Oleh karena itu, tulisan ini menjelaskan lebih jauh mengenai hubungan antara integrasi dalam pemerintahan supranasional dan kedaulatan sebuah negara.
\end{abstract}

Kata Kunci: integrasi, kedaulatan, Uni Eropa, pengungsi. 


\section{PENDAHULUAN}

Lebih dari 2,5 juta orang mengungsi akibat perang saudara yang terjadi di Syria sejak Maret 2011 (syrianrefugees.eu. 2013). Selain itu, masih 6,5 juta jiwa terlantar dan terperangkap di Syria dan menjadikan krisis kelaparan pengungsi terburuk sejak 50 tahun sejarah UN World Food Programme (Jamieson. 2013). Permasalahan ini tidak hanya mendapatkan perhatian Perserikatan Bangsa-Bangsa (PBB) sebagai pemerintahan global ${ }^{1}$, tapi Uni Eropa (UE) sebagai organisasi regional turut turun tangan menangani masalah pengungsian ini. Komisi Eropa bersiap untuk memberikan bantuan sejumlah 202 juta US\$ kepada orang-orang yang terkena dampak dari krisis Syria (Jamieson. 2013). Namun, di lain sisi, beberapa Non-Governmental Organization (NGO) memberitakan bahwa terdapat pengusiran secara paksa oleh otoritas Yunani sebagai salah satu anggota UE kepada pengungsi Syria yang mencari suaka (enetenglish.gr). Hal ini tentunya bertolak belakang dengan apa yang telah UE lakukan.

Kondisi ini berbalik dengan negara EU lain yang telah menerima pengungsi dari Syria. Jerman dan Swedia merupakan dua negara yang banyak menerima pengungsi Syria. Sebanyak 41.000 pencari suaka dari Syria telah ditampung sebagian besar di dua negara UE tersebut (irinnews.org). Fenomena penolakan yang dilakukan Yunani ini juga bertentangan dengan nilai-nilai dalam Common European Asylum System (CEAS) sebagai standard yang dipakai oleh negara-negara UE dalam memperlakukan pencari suaka. Terlebih lagi, Robert Cooper, seorang diplomat UE, menyatakan bahwa konsep supranasional yang dikembangkan oleh UE dianggap sebagai konsep yang cocok diterapkan di era pemerintahan global karena setiap negara UE diwajibkan tunduk terhadap otoritas legal supranasional (Cooper dalam Fonte. 2011).

Penolakan Yunani ini kemudian memunculkan pertanyaan yang dibahas dalam tulisan ini yaitu bagaimana otoritas legal supranasional dalam UE menjadi acuan bagi negara-negara di dalamnya, termasuk Yunani dalam merumuskan serta menjalankan kebijakan dalam negerinya? Kemudian, sejauh mana kedaulatan negara UE berhadapan dengan otoritas legal supranasional tersebut dalam kasus penanggulangan pengungsi yang termaktub dalam CEAS?

Pada dasarnya, UE merupakan organisasi regional yang dianggap intensitas integrasinya cukup tinggi. Namun, integrasi ini ternyata tidak sampai menyerahkan kedaulatan sebuah negara kepada kedaulatan supranasional. Frank Decker (2002) berpendapat bahwa konsekuensi globalisasi adalah peningkatan kebutuhan mengenai integrasi yang lebih lanjut, namun, integrasi ini tidak menjamin otoritas dalam sebuah negara dapat dengan mudah diserahkan kepada UE. Oleh karena itu, apa yang dilakukan oleh Yunani dalam penolakan terhadap pengungsi Syria bukan disebabkan oleh posisi Yunani sebagai anggota UE yang tunduk terhadap nilai-nilai CEAS, melainkan posisi Yunani yang masih memiliki kedaulatan terhadap negaranya. Sehingga, integrasi UE yang sedemikian rupa tidak menjamin setiap masalah sebuah negara anggotanya dapat diakomodasi untuk dijadikan masalah UE secara keseluruhan.

Tulisan ini selanjutnya dikembangkan dalam empat bagian untuk menjawab permasalahan. Pertama, pendekatan teoritis mengenai integrasi UE sehingga kemudian bagian ini mendefinisikan integrasi yang terjadi di UE khususnya yang termasuk dalam

\footnotetext{
1. Governance atau pemerintahan menurut Young adalah institusi sosial atau seperangkat aturan yang digunakan untuk memandu perilaku siapa saja yang terikat dalam praktek-praktek sosial yang telah ditentukan. Sedangkan government atau pemerintah adalah organisasi atau entitas material yang dibentuk untuk mengelola ketetapan-ketetapan yang ada dalam sistem governance (Knight. 2001: 3). Dengan kata lain, government merupakan organisasi yang menjalankan peraturan-peraturan yang telah dibentuk oleh governance.
} 
CEAS. Kedua, perkembangan CEAS sebagai salah satu nilai yang berkembang di UE yang digunakan oleh negara-negara UE dalam menangani masalah pengungsian. Ketiga, peran Yunani dalam menangani masalah pengungsian Syria serta penyebab yang menghambat Yunani dalam mengaplikasikan nilai UE yang dalam hal ini adalah CEAS. Terakhir adalah kesimpulan yang dihimpun beradasarkan teori dan data yang telah didapat pada bagianbagian sebelumnya.

\section{INTEGRASI UE SEBAGAI ACUAN PEMERINTAHAN GLOBAL}

Setiap negara di seluruh dunia tentu saja memiliki kebutuhan dan kepentingan yang perlu dipenuhi. Kebutuhan-kebutuhan yang diperlukan oleh setiap negara bisa lebih mudah diselesaikan apabila setiap negara berkenan untuk menjalin hubungan kerja sama antara satu negara dengan negara lain. Untuk menguatkan kerja sama antar negara dapat diwujudkan dengan pembentukan organisasi dalam bidang ekonomi, politik, lingkungan, sosial, dan sebagainya. Salah satu bentuk kerjasama ini adalah kerjasama regional yang didasarkan pada cakupan wilayahnya termasuk UE. UE sendiri adalah organisasi Internasional yang didirikan oleh negara-negara Eropa yang dibentuk untuk membuat dan meningkatkan integrasi kerja sama antar negara anggotanya. Kerja sama ini lebih mengacu pada pembuatan satu struktur pemerintahan bersama di Eropa sebagai landasan perumusan dan keputusan terhadap masalah-masalah yang terjadi di negara-negara Eropa.

Prinsip utama dalam hukum Eropa ialah bahwa hukum UE menjadi sumber hukum yang lebih tinggi daripada hukum nasional. Atau dengan kata lain, "EU-sourced laws takes precedence over domestic laws" (lawsociety.org.uk). Hal ini berarti bahwa sekali suatu hukum UE berlaku di negara anggota, maka tidaklah dapat dibenarkan apabila suatu negara anggota mempertahankan atau membuat hukum yang bertentangan dengan hukum UE. Keunggulan hukum Eropa ini bukan hal yang baru dan merupakan prinsip yang berkedudukan kuat (lawsociety.org.uk), Robert Cooper, seorang diplomat UE mengembangkan teori yang dinamakan negara posmodern dalam menganalisis keunggulah hukum UE ini. Yang dimaksud negara posmodern oleh Cooper adalah kemampuan UE yang mampu menampung kedaulatan negara di dalamnya sehingga negara di dalam UE dapat menerima otoritas legal supranasional sebagai otoritas di atas peraturan nasional (Cooper dalam Fonte. 2011). Oleh karena itu, negara-negara yang termasuk dalam UE memiliki tanggung jawab untuk mengikuti otoritas supranasional yaitu UE. Sehingga, negara posmodern ini dianggap sebagai tipe negara baru yang cocok diterapkan di era pemerintahan global (John Fonte. 2011: 27).

Konsep ini merupakan salah satu konsep yang dapat mengatasi keterbatasan pemerintahan global semacam PBB yang belum mampu mengadaptasikan kedaulatan masing-masing negara anggotanya. PBB awalnya dianggap sebagai pemerintahan global yang berguna untuk menyelesaikan masalah dilema internasional yang tidak dapat dihadapi oleh negara sekelas Amerika Serikat sekalipun (Margaret dan Mingst. 2004). Namun, pandangan liberal maupun konstruktivis menekankan bahwa politik domestik memegang peran kunci dalam menentukan kebijakan negara, komitmen internasional, dan perilaku dalam global governance (Margaret dan Mingst. 2004). Sehingga, diperlukan integrasi yang cukup tinggi agar pemerintahan global dapat menjadi acuan bagi negaranegara di dalamnya untuk bersama-sama mengatasi masalah bersama. Oleh karena itu, pemerintahan global bisa dianggap berhasil ketika berhadapan dengan masalah bersama seperti terorisme, kerusakan lingkungan, HIV/AIDS, termasuk masalah pengungsian.

Integrasi UE ini kemudian oleh Luk Van Langenhove dapat dianggap sebagai langkah yang cukup relevan dalam menghadapi kompleksitas pemerintahan global. Langenhove (2004) berpendapat bahwa, apa yang dilakukan UE adalah sebuah bentuk 
inovasi dan hal ini dapat menjadi acuan terhadap permasalahan tentang sistem pemerintahan yang multi level dan kompleks karena di dalam UE terdapat kerjasama antar negara yang dapat memindahkan kekuatan dalam sebuah negara dalam sebuah kerangka legal yang kuat. Keterikatan negara-negara kawasan Eropa dalam sebuah kerangka legal yaitu UE menjadikan negara anggota UE lebih mudah untuk mengaplikasikan nilai-nilai yang ada dalam UE.

Integrasi ini pada dasarnya disebabkan karena sejak tahun 1950-an, UE telah menjadi pionir dalam hal integrasi regional. Kesuksesan ini dikarenakan empat prinsip yang ada dalam proyek UE (Cameron. 2010). Pertama, bentuk komunitas supranasional sudah dikerangkakan oleh Robert Schuman dari Prancis dan Konrad Adenauer dari Jerman. Bentuk komunitas supranasional ini lebih dari sekedar balance of power sebagai konsep umum dalam hubungan antar negara. Kedua, kepemimpinan awalnya dipegang oleh Jerman dan Prancis. Sehingga, ketika ada permasalahan yang dapat menghambat proses integrasi, maka kedua negara ini memiliki tanggung jawab untuk meluruskan kembali proses integrasi. Ketiga, harapan politik dalam UE adalah adanya pembagian kedaulatan dan membangun institusi yang kuat dan legal demi pencapaian integrasi. Keempat, adanya pendekatan konsensus yang menggabungkan nilai-nilai solidaritas dan toleransi. Pendekatan UE didasarkan pada tidak adanya isolasi terhadap sebuah negara ketika negara anggota tersebut menghadapi masalah besar seperti krisis. Keempat pendekatan ini dianggap telah mampu mempertahankan Eropa dari berbagai krisis yang melanda di setiap negara anggotanya.

Dengan kata lain, tingkat integrasi yang tinggi di UE menjadi salah satu faktor penerapan pemerintahan global secara efektif. Dengan integrasi ini, maka aturan, norma, dan nilai yang terkandung di dalam sebuah pemerintahan global dapat diaplikasikan oleh seluruh anggota negara pemerintahan global untuk memperoleh kekuatan dan pengaruh kolektif yang lebih besar. Selain itu, segala permasalahan dalam negeri suatu negara di UE menjadi masalah bersama secara regional sesuai dengan nilai toleransi dan solidaritas antar anggota. Sehingga dalam praktiknya, negara-negara anggota UE mendelegasikan sebagian kuasa mereka kepada lembaga UE dalam pengambilan keputusan terhadap masalah-masalah tertentu yang melibatkan kepentingan bersama yang dapat diselesaikan secara demokratis pada tingkat regional (ec.europa.eu).

Perumusan kebijakan-kebijakan utama yang dibentuk oleh UE selalu disamakan dengan faktor-faktor eksternal yang kemudian dipengaruhi oleh hal-hal yang menjadi perhatian organisasi seperti hak asasi manusia, bantuan kemanusiaan, perdagangan, ilmu pengetahuan, penanganan krisis, dan berbagai masalah bersama lain (hdl.handle.net). Dalam bidang hak asasi manusia, penyusunan kebijakan oleh UE dilakukan dengan dasar universal yaitu bahwa semua manusia memiliki hak yang sama untuk memperoleh kehidupan dan perlindungan yang layak seperti yang tercantum dalam delapan pedoman tentang hak asasi manusia (ec.europa.eu). Sehingga, perhatian mengenai hak asasi manusia dalam kebutuhannya terhadap perlindungan hidupnya diatur dan diawasi oleh UE. Maka terbentuknya CEAS merupakan salah satu implementasi penerapan nilai-nilai hak asasi manusia yang menjadi perhatian negara-negara anggota UE secara keseluruhan.

Salah satu nilai integrasi UE yang menjadi fokus pembahasan dalam artikel ini adalah nilai CEAS yang menjadi sistem standar untuk mengatasi masalah pengungsian dan pencarian suaka atau perlindungan negara-negara anggota UE. Namun, tingkat integrasi di UE ini masih mengalami permasalahan seperti yang dijelaskan oleh Margaret dan Mingst (2004) yang menyatakan bahwa politik domestik masih mendominasi dalam pemerintahan global termasuk dalam level integrasi yang ada dalam UE. Oleh karena itu, bagian selanjutnya dijelaskan mengenai implementasi CEAS oleh Yunani dalam menangani 
masalah pengungsi Syria serta pengaruh domestik Yunani yang dapat mempengaruhi implementasi kebijakan tersebut.

\section{PERKEMBANGAN CEAS DALAM UE}

UE dibentuk bukan sebagai pemerintah regional walaupun di dalam UE terdapat parlemen UE, UE masih termasuk sebagai pemerintahan global. Posisi ini muncul karena pada dasarnya tidak ada aktor tunggal yang secara hirarki memiliki otoritas di atas negara atau yang disebut dengan pemerintah global sedangkan pemerintahan global sendiri merupakan aktivitas kolektif, aturan, mekanisme, baik formal maupun informal yang eksis secara internasional (Margaret dan Mingst. 2004). Dengan kata lain, UE tidak memiliki pemimpin secara struktural yang mengatur seluruh negara anggota UE. Oleh karena itu, dalam upayanya untuk menghadapi tantangan global, UE lebih memilih jalan multilateralisme.

Dalam urusan pengungsi, CEAS merupakan standard bagi negara-negara UE ketika negara-negara UE menghadapi masalah pengungsian. Pada tahun 1999, UE bekerja untuk membangun kerangka legislatif dalam penanganan masalah pengungsi yang kemudian terbentuklah CEAS (ec.europa.eu) yang didasarkan pada Article 14 dalam Universal Declaration of Human Right tahun 1948 yang menyatakan bahwa terdapat hak-hak pencari suaka untuk terhindar dari tindakan kekerasan dari negara lain (UNHCR). Pengaturan masalah pengungsi ini kemudian pada tahun 1999 hingga 2005 menghasilkan beberapa ketentuan dalam penanganan masalah pengungsi. Pengaturan mengenai solidaritas finansial yang menghasilkan European Refugee Fund, lalu perlindungan pengungsi dalam Temporary Protection Directive, dan Family Reunification Directive merupakan hasil pengaturan dalam CEAS (ec.europa.eu).

Masing-masing ketentuan ini kemudian dijadikan rujukan bagi negara-negara UE yang menghadapi masalah pengungsi baik pengungsi yang berasal dari negara UE sendiri maupun dari luar UE. European Refugee Fund diaplikasikan dengan cara membantu negara-negara UE dalam menangani masalah pengungsi agar konsistensi akses, keadilan, dan keefektifan prosedur pemberian suaka dapat terjamin (ec.europa.eu). Temporary Protection Directive adalah sebuah tindakan yang diberikan kepada pengungsi dari negaranegara bukan UE yang tidak dapat kembali ke negara asalnya. Tindakan ini dilakukan secara sementara dan segera karena standard sistem pemberian suaka masih dalam proses yang cukup rumit. Tindakan ini dilakukan karena dua sebab yaitu untuk mengurangi disparitas kebijakan UE dengan situasi gelombang pengungsian yang tinggi dan mempromosikan solidaritas dan pembagian beban di antara negara UE sebagai negara penerima pengungsi. Yang terakhir adalah Family Reunification Directive yaitu sebuah kebijakan yang memungkinkan bagi keluarga pengungsi untuk disatukan kembali dengan beberapa syarat yang ada.

Dengan kata lain, UE memiliki nilai yang tinggi terhadap penanganan pengungsi baik dari segi finansial, perlakuan, hingga paska pengungsian seperti penyatuan keluarga pengungsi yang terpisah. Namun, hal ini tidak tampak dalam perlakuan Yunani ketika kedatangan pencari suaka dari Syria. Berdasarkan laporan dari beberapa NGO, Yunani melakukan pengusiran secara paksa terhadap pencari suaka dari Syria yang kemudian ditanggapi oleh United Nation High Commissioner for Refugees (UNHCR) melalui juru bicaranya yaitu Adrian Edwards yang memperingatkan Yunani dengan berkomentar bahwa pengajuan batas seperti pemagaran dan pengelakan dapat membahayakan pengungsi dan seperti memperlakukan pengungsi seperti pengemis (www.novinite.com/). Jika dikaitkan dengan nilai-nilai CEAS, maka tindakan Yunani ini merupakan pelanggaran terhadap nilai-nilai yang telah dikerangkakan dalam CEAS. 
Pelanggaran yang dilakukan oleh Yunani ini kemudian menjadi sorotan pemerintahan global dalam hal ini UNHCR. Hal ini karena pada dasarnya, seluruh anggota Uni Eropa (UE) menandatangani dan sekaligus meratifikasi konvensi PBB tentang status pengungsi yaitu Conventing Relating to the Status of Refugee of 28 July 1951 atau disebut juga 1951 Refugee Convention beserta the Protocol Relating to the Status of Refugees of 31 January 1967 atau disebut juga protocol 1967 dan telah menegaskan kembali komitmen yang paling penting untuk keselamatan semua orang yang berisko terhadap tindakan penyiksaan atau perlakuan tidak manusiawi atau merendahkan harkat dan martabatnya di negara asal mereka. Sistem suaka di Eropa mengacu pada Dublin II Regulation yaitu peraturan yang menyediakan mekanisme untuk menentukan negara anggota Uni Eropa mana yang bertanggung jawab untuk memeriksa permohonan suaka yang diajukan oleh warga negara dari negara ketiga (Arista. 2013).

Oleh karena itu, penolakan terhadap pencari suaka di Yunani mendapatkan perhatian khusus UNHCR yang langsung mengkritik keberadaan UE sebagai organisasi regional yang menaunginya. Juru bicara UNHCR berpendapat bahwa kegagalan sistem suaka yang memberikan jaminan perlindungan bagi pengungsi di Yunani seharusnya ditanggulangi di level UE. Sehingga, UE harusnya siap melakukan nilai-nilai yang terkandung dalam CEAS termasuk Temporary Protection Directive dan respon lain yang sesuai jika keadaan membutuhkan hal tersebut. Hal ini karena pada dasarnya, hak-hak pencari suaka harus dijunjung tinggi oleh setiap negara setiap waktu (UNHCR. 2013). Kritik UNHCR ini masih menunjukkan pengakuan bahwa UE masih sebagai organisasi antar negara di kawasan Eropa yang memiliki tingkat integrasi yang tinggi. Sehingga, ketika salah satu negara anggotanya berperilaku menyimpang, maka UE memiliki tanggung jawab atas penyimpangan tersebut seperti dalam kasus penolakan pengungsi Syria oleh Yunani.

\section{IMPLEMENTASI CEAS OLEH YUNANI}

Dalam kasus perang saudara yang terjadi di Syria, seperti kasus pengungsian lain, pengungsi dari Syria berusaha untuk menyelamatkan jiwanya dengan menjadi pengungsi. Sejak konflik pecah pada tahun 2011, PBB mencatat bahwa korban meninggal dunia berjumlah hingga lebih dari 100.000 jiwa dan diestimasikan bahwa 5.000 korban meninggal tiap bulannya (AFP. 2013). Dengan kondisi seperti ini, maka sebagian besar warga Syria lebih memilih untuk mengungsi untuk menyelamatkan jiwa mereka. Kuhlman menggambarkan bahwa dalam kasus pengungsian, bukan surga yang pengungsi cari melainkan cara keluar dari neraka di mana tempat mereka berasal atau Kuhlman memberi julukan kepada pengungsian sebagai 'involuntary international migrants' (Kuhlman dalam Haddad 2008. 29). Sehingga, tidak ada faktor penarik dari negara tuan rumah atau negara tujuan pengungsi selain keamanan yang diharapkan dari pengungsi tersebut.

Keterpaksaan migrasi Syria ini kemudian memunculkan masalah bagi negaranegara tujuan pengungsian. Seiring dengan krisis yang belum usai, jumlah pengungsi terus meningkat dan memaksa negara tujuan pengungsian ini seperti Jordania, Turki, dan Libanon berjuang untuk menampung pengungsi tersebut (Karakaya. 2013). Masalah lain muncul ketika jumlah donasi internasional yang tidak mampu menutup keseluruhan pengeluaran untuk masalah ini. Turki misalnya, telah menghabiskan dana sebesar 1,5 miliar US\$ untuk masalah pengungsian sedangkan hanya 116 juta US\$ masuk dari donor luar negeri (Aydoğdu dalam Karakaya. 2013). Selain dari segi pendanaan, negara-negara penerima pengungsi ini juga mengalami kepadatan pengungsi yang cukup tinggi. Negaranegara yang memiliki kepadatan pengungsi tinggi dari Syria ini adalah Jordania yang telah menampung sebanyak 569.000, Libanon sebanyak 849.000, dan Turki sebanyak 553.116 (UNHCR. 2013). Oleh karena itu, selain kebutuhan pendanaan, pengungsi juga dihadapkan 
pada pencarian negara tujuan baru dan Yunani merupakan harapan baru bagi para pengungsi karena posisi Yunani yang berbatasan langsung dengan Turki dan sebagai pintu masuk ke Eropa dari Asia.

Ada beberapa rute yang dilalui oleh pengungsi Syria untuk masuk ke Eropa karena penuhnya penampungan pengungsi di Libanon, Jordania, dan Turki (Fargues dan Fandrich. 2012: 5). Pertama, melalui laut Mediterania yang kemudian berlanjut ke negara-negara seperti Yunani, Cyprus, Malta, atau Italia. Kedua, jalur udara yang memungkinkan pengungsi Syria untuk langsung menuju ke negara tertentu di Eropa. Namun, perjalanan melalui udara ini menyulitkan pendataan pengungsi yang mengungsi dari Syria ke Eropa. Ketiga adalah jalur darat yang melalui Yunani atau Bulgaria. Dengan jalur ini baik pengungsi yang memiliki visa maupun tidak, bisa mendapatkan suaka atau menetap dalam situasi khusus atau bahkan meneruskan perjalanan ke negara UE yang dituju. Oleh karena dua rute yaitu datar dan air melalui batas Yunani, maka Yunani memiliki posisi yang signifikan dalam hal perpindahan pengungsi secara massal ini.

Sebagai bagian dari UE, Yunani seharusnya mengimplementasikan nilai-nilai CEAS yang menjadi rujukan UE dalam menangani masalah pengungsi. UE sendiri telah melakukan beberapa nilai yang terkandung dalam CEAS dalam menangani masalah pengungsi Syria ini. Setidaknya UE telah mendonasikan bantuan finansial terhadap pengungsi yang berada di beberapa negara yaitu Jordania, Libanon, dan Turki. Sudah 1,9 miliar € telah dikerahkan oleh UE ke negara Syria dan negara tetangganya baik dari komisi maupun gabungan dana dari negara anggota UE untuk menangani dampak konflik yang terjadi di Syria termasuk masalah pengungsian (europa.eu). Namun, untuk poin kedua yaitu pemberian perlindungan sementara, beberapa negara UE masih belum menerapkan pengaturan ini terutama Yunani.

Judith Sunderland, sorang peneliti dalam Human Rights Watch, menyimpulkan bahwa kedatangan rakyat Syria yang mencari suaka di EU menghadapi undian atau perjudian tergantung negara mana yang mampu dicapai oleh pencari suaka ini (hrw.org). Yang dimaksudkan dengan undian ini adalah bahwa tidak adanya perlakuan yang sama di negara-negara UE dalam menerima kedatangan pengungsi ini. Hal ini terlihat ketika Jerman maupun Swedia yang tercatat sebagai negara penerima suaka pengungsi Syria terbanyak di UE, sedangkan sejak tahun 2011, sebanyak 10.000 orang Syria yang mencari suaka di Yunani, hanya enam yang mampu memperoleh perlindungan (hrw.org). Fenomena ini menunjukkan bahwa dalam integrasi UE, politik domestik masih bisa mempengaruhi negara anggota UE dalam bertindak.

Ada beberapa sebab domestik yang menyebabkan Yunani menolak bahkan mengusir pengungsi dari Syria. Pertama, arus pengungsi Syria yang tidak kunjung reda sehingga kamp pengungsian penuh sesak sedangkan Yunani sendiri tidak mampu menangani proses suaka dengan lancar. Kedua, krisis ekonomi yang melanda Yunani sejak tahun 2008. Krisis ini juga menjadi alasan bagi UE dalam mengklarifikasi penolakan pengungsi Syria yang terjadi di Yunani. Krisis ini dianggap krisis yang parah sehingga pemerintah Yunani lebih memilih berhemat dan sibuk membenahi masalah keuangan domestiknya agar bisa mensejahterakan penduduknya. Sehingga, pemberian kebutuhan dan akomodasi terhadap pengungsi tidak menjadi fokus utama (Peter. 2013). Ketiga, Yunani menganggap pengungsi Syria sebagian besar memiliki penyakit menular yang bisa membahayakan penduduk Yunani sendiri. Sehingga, demi keamanan nasional, maka Yunani mengusir sebagian besar pencari suaka dari Syria (Beuthner dan Kostermans. 2012).

UNHCR sendiri menyatakan bahwa penolakan dan pengembalian pengungsi atau pencari suaka mengarahkan pencari suaka tersebut ke resiko yang lebih tinggi dan 
memberikan dampak trauma bagi pengungsi (UNHCR. 2013). Bahkan, UNHCR menyebut peristiwa ini sebagai krisis kemanusiaan yang seharusnya tidak terjadi di wilayah UE (UNHCR. 2013). Oleh karena itu, UNHCR memberikan beberapa rekomendasi untuk Yunani dalam rangka penanganan masalah pengungsi Syria. Pertama, UNHCR menganggap bahwa pergerakan masyarakat Syria ini termasuk dalam kelompok pengungsi yang ada dalam konvensi 1951 mengenai status pengungsi. Oleh karena itu, Yunani harus memberikan proteksi internasional dan mengijinkan pengungsi tersebut mengakses batas teritori Yunani untuk mendapatkan keamanan di Yunani. Kedua, Yunani dilarang untuk mengembalikan pengungsi Syria sebelum kondisi Syria kembali stabil. Terlebih lagi bahwa tidak ada kekerasan untuk memaksa pengungsi untuk kembali dan hal ini termasuk dalam rekomendasi UNHCR. Ketiga, UNHCR mengajak Yunani untuk lebih mengekspresikan solidaritas dengan cara membagi wilayah dengan pengungsi serta bertanggung jawab terhadap keamanan pengungsi. Keempat, sebagai anggota UE, Yunani juga memiliki tanggung jawab untuk menfasilitasi penyatuan kembali keluarga pengungsi Syria baik keluarga tersebut berada dalam Yunani maupun di negara anggota UE lain.

Selain itu, posisi Yunani yang berada di perbatasan menjadikan Yunani sebagai tempat kedatangan awal pengungsi dari luar Eropa. Sehingga, berdasarkan aturan yang berlaku dalam Peraturan Dublin, maka setiap negara yang didatangi pengungsi pertama kali, maka negara tersebut berkewajiban untuk memproses pemberian suaka (Peter. 2013). Peraturan ini kemudian membawa pencari suaka dari Syria untuk mencari jalur baru untuk mencapai daratan Eropa. Sehingga, tidak jarang pencari suaka ini kemudian melewati jalur laut untuk sampai langsung ke Italia. Sebanyak 7.500 orang Syria datang ke Italia melalui rute Laut Tengah sejak Januari 2013 (Yaghmaian. 2013). Dilihat dari sejarah, rute ini merupakan rute yang mematikan bagi pencari suaka. Pada tahun yang sama, sebanyak kurang lebih 300 orang Afrika meninggal ketika mencoba menuju Eropa dengan melalui jalur Laut Tengah (Milanovic. 2013).

Profesor Behzad Yaghmaian (2013) berpendapat bahwa krisis kemanusiaan mengenai pengusiran pengungsi di Yunani ini tidak dapat dilihat sebagai satu ketidakmampuan Yunani sebagai negara perbatasan dalam menanggulangi masalah pengungsi ini. Sebagai basis ad hoc, Perancis, Inggris, dan beberapa negara UE lain dianggap telah mengacuhkan Peraturan Dublin karena hanya negara yang berada di perbatasan atau Yunani yang bertanggung jawab terhadap pemberian suaka terhadap pengungsi. Dengan sistem ini, maka Yunani yang telah mengalami keterpurukan ekonomi domestik semakin dibebani dengan tanggung jawab sebagai penjaga perbatasan Eropa dari melonjaknya jumlah pengungsi dari kawasan Arab khususnya dari Syria.

\section{KESIMPULAN}

Integrasi Eropa dalam bentuk UE dianggap sebagai integrasi tingkat tinggi dalam konteks integrasi regional. Integrasi dibutuhkan agar penerapan nilai-nilai dalam pemerintahan regional dapat diimplementasikan oleh negara-negara anggota UE secara keseluruhan. Kondisi ini dapat terwujud karena adanya nilai kebersamaan, solidaritas, dan toleransi antar negara anggota yang dapat dijadikan acuan dalam perumusan kebijakan bersama. Namun, integrasi ini belum sepenuhnya menggabungkan kepentingan atau kedaulatan masing-masing negara dalam satu wadah organisasi supranasional. Masih terdapat kepentingan dan kondisi domestik yang menjadi penghambat proses integrasi ini. Pengusiran Yunani terhadap kedatangan pengungsi dari negara yang sedang berkonflik yaitu Syria merupakan salah satu contoh celah integrasi yang digaungkan oleh UE sebagai keunggulan UE. 
Kondisi domestik Yunani yang sedang dilanda krisis ekonomi dijadikan alasan Yunani dalam menolak kedatangan pengungsi ini. Penolakan ini tentunya bertentangan dengan nilai-nilai yang telah disepakati bersama anggota UE dalam CEAS yaitu memberikan perlindungan kepada pengungsi. Kondisi ini menggambarkan bahwa masih adanya otoritas negara atau kedaulatan negara yang tidak secara utuh diserahkan kepada pemerintahan supranasional seperti yang dijelaskan oleh Decker (2002) dan Margareth dan Mingst (2004). Selain itu, kebijakan yang dirumuskan dalam pemerintahan supranasional ini dalam pelaksanaannya tidak menjadi tanggung jawab bersama melainkan tanggung jawab masing-masing negara karena ketika salah satu negara anggota mengalami masalah pengungsian seperti yang terjadi di Yunani, negara lain seperti Perancis dan Inggris dianggap telah mengacuhkan kesepakatan bersama tersebut seperti yang dijelaskan oleh Profesor Yaghmaian (2013). Dengan kata lain, kadaulatan negara masih dominan ketika dihadapkan dengan kebijakan-kebijakan pemerintahan regional yang integratif.

\section{DAFTAR RUJUKAN}

AFP. (2013). More Than 2,000 Killed in Syria Since Ramadhan Began. Diakses dari http://www.timesofoman.com/News/Article-20325.aspx pada 22 Desember 2013.

Anon. (2008). A guide to the Treaty of Lisbon. European Union insight. diakses dari http://www.lawsociety.org.uk/documents/downloads/guide_to_treaty_of_lisbon.p df pada 17 Januari 2014.

Anon. (2012). EU: Provide Protection for Syrian Refugees. Diakses dari http://www.hrw.org/news/2012/12/23/eu-provide-protection-syrian-refugees pada 17 Januari 2014.

Anon. (2013). NGO Claims Greek Authorities are 'Pushing Back' Syrian Refugees. Diakses dari http://www.enetenglish.gr/?i=news.en.article\&id=1599 pada 22 Desember 2013.

Anon. (2013). No Welcome Mat for Syrian in Europe. Diakses dari http://www.irinnews.org/report/98826/no-welcome-mat-for-syrians-in-europe pada 17 Januari 2014.

Anon. (2013). UN Warns Greece, Bulgaria: Don't Turn Away Syria Refugees. Diakses dari http://www.novinite.com/view_news.php?id=155589 pada 16 Januari 2014

Anon. tt. Syrian Refugees: A Snapshot of the Crisis- In the Middle East and Europe. Diakses dari http://syrianrefugees.eu/ pada 22 Desember 2013.

Arista, Riski S. (2013). Pemindahan Pencari Suaka dalam Pengaturan Pencari Suaka Region di Uni Eropa Dikaitkan dengan Prinsip Non-Refoulement Menurut Hukum Internasional dan Standar Hak Asasi Manusia Internasional. Skripsi Sarjana. Bandung: Fakultas Hukum Universitas Padjadjaran.

Beuthner, Beatrix dan Dyan Kostermans. (2012). Upaya Uni Eropa untuk Batasi Pengungsi. diakses dari http://www.dw.de/upaya-uni-eropa-untuk-batasi-pengungsi/a15800278 pada 17 Januari 2014.

Cameron, Fraser. (2010). The European Union as a Model for Regional Integration. Working Paper: CFR's International Institutions and Global Governance.

Decker, Frank. (2002). Governance Beyond the Nation State. Reflection on the Democratic Deficit of the European Union. Journal of European Public Policy, 9 (2/2002).

European Comission. (2013). Common European Asylum System. Diakses dari http://ec.europa.eu/dgs/home-affairs/what-we-

do/policies/asylum/index_en.htm pada 16 Januari 2014. 
(2013). Syria Crisis: EU Delivers on Its Pledges and Mobilises Another $€ 85$ Million for Syria and Jordan. Diakses dari http://europa.eu/rapid/pressrelease_IP-13-999_en.htm pada 17 Januari 2014.

Fargues, Philippe dan Christine Fandrich. (2012). The European Response to the Syrian Refugee Crisis: What Next? MPC RR 2012/14, Robert Schuman Centre for Advanced Studies, San Domenico di Fiesole (FI): European University Institute.

Fonte, John. (2011). Sovereignty or Submission: Liberal Democracy of Global Governance? Foreign Policy Research Institute.

Haddad, Emma. (2008). The Refugee in International Society: Between Sovereignty. New York: Cambridge University Press.

Jamieson, Alastair. (2013). Syria Refugee Crisis is 'Greatest Humanitarian Tragedy of Our Times': UN. Diakses dari http://worldnews.nbcnews.com/_news/2013/12/18/21954277-syria-refugeecrisis-is-greatest-humanitarian-tragedy-of-our-times-un pada 22 Desember 2013.

Karakaya, Irem. (2013). Syrian refugees Face Tougher Times as Host Countries Problems Worsen. Diakses dari http://www.todayszaman.com/news-321269-syrianrefugees-face-tougher-times-as-host-countries-problems-worsen.html pada 22 Desember 2013.

Karns, P. Margaret dan Karen A. Mingst. (2004). International Organizations: The Politics and Processes of Global Governance. Boulder: Lynne Rienner.

Langenhove, Luk Van. (2004). Regional Integration and Global Governance. UNU-CRIS Occasional Papers 0-2004/4.

Milanovic, Branko. (2013). The Economic Causes of Migration. Diakses dari http://www.theglobalist.com/economic-causes-migration/ pada 17 Januari 2014.

Peter, Laurence. (2013). Q\&A: Migrants and Asylum in the EU. Diakses dari http://www.bbc.co.uk/news/world-europe-24583286 pada 17 Januari 2014.

UNHCR. (2012). Syria Crisis: UNHCR Urges European Union States to Honour Their Asylum Sistem Principles. Diakses dari http://www.unhcr.org/507d4c586.html pada 15 Januari 2014.

Yaghmaian, Behzad. (2013). Syrian Refugees: A Need for Global Burden Sharing. Diakses dari http://www.theglobalist.com/syrian-refugees-need-global-burden-sharing/ pada 17 Januari 2014. 